\begin{tabular}{|c|l|}
\hline Title & A b Initio Study of Xe A dsorption on Graphene \\
\hline Author(s) & Sheng, Li; Ono, Y uriko; Taketsugu, Tetsuya \\
\hline Citation & $\begin{array}{l}\text { Journal of Physical Chemistry C, 114(8), 3544.3548 } \\
\text { https://doi.org/40.1021/jp907861c }\end{array}$ \\
\hline Issue Date & 2010-03-04 \\
\hline Doc URL & http://hdl.handle.net/2115/47461 \\
\hline Type & article \\
\hline File Information & JPCC1148_3544_3548.pdf \\
\hline
\end{tabular}

Instructions for use 


\title{
Ab Initio Study of Xe Adsorption on Graphene
}

\author{
Li Sheng, $*,+, *$ Yuriko Ono,, and Tetsuya Taketsugu $*, \neq$ \\ Department of Chemistry, Natural Science Research Center, Academy of Fundamental and Interdisciplinary \\ Sciences, Harbin Institute of Technology, Harbin 150080, People's Republic of China, and Division of \\ Chemistry, Graduate School of Science, Hokkaido University, Sapporo 060-0810, Japan
}

Received: August 14, 2009; Revised Manuscript Received: December 30, 2009

\begin{abstract}
The adsorption of Xe on graphene has been systematically investigated by ab initio MP2 calculations using Dunning's correlation-consistent basis sets. The polycyclic aromatic hydrocarbon (i.e., coronene) is employed to model the graphene surface. The adsorption energies at three high-symmetry sites on the surface are calculated at the MP2/cc-pVTZ/cc-pVDZ-PP level. Our results show that Xe preferentially occupies the hollow site on the graphene surface. The equilibrium distance of Xe at the hollow site is calculated as $3.56 \AA$, which is in excellent agreement with the available experimental value of $3.59 \pm 0.05 \AA$. The corresponding binding energy at the hollow site is calculated as $-142.9 \mathrm{meV}$, whereas the binding energies at the bridge and on-top sites are calculated as -130.8 and $-127.4 \mathrm{meV}$, respectively. The adsorption of polar molecules, $\mathrm{XeF}$ and $\mathrm{XeBeO}$, on graphene is also investigated to analyze the site preference.
\end{abstract}

\section{Introduction}

Rare-gas atoms have long been the classical adatoms for the study of physisorption mainly because of their notable inertness. The adsorptions of rare-gas atoms on graphite or close-packed transition-metal surfaces have been extensively investigated in recent years. The early experimental analysis by spin-polarized lowenergy electron diffraction (SPLEED) and theoretical studies based on empirical pair potentials had concluded that rare-gas atoms prefer to adsorb at the hollow site on graphite and metal surfaces (see Figure 1 for illustration). ${ }^{1-6}$ However, SPLEED analysis showed that the perpendicular distance from Xe to the $\mathrm{Pt}(111)$ surface was $4.2 \AA$, which is much longer than the expected hard sphere distance (van der Waals radii for Xe and Pt atoms are 2.16 and $1.75 \AA{ }^{7}$ respectively). Scanning tunneling microscopy (STM) and low-energy electron diffraction (LEED) experiments were consequently performed, respectively, for $\mathrm{Xe}$ on $\mathrm{Pt}(111)^{8}$ and $\mathrm{Xe}$ on $\mathrm{Ru}(0001),{ }^{9,10} \mathrm{Cu}(111),{ }^{11}$ and $\mathrm{Pt}(111) .{ }^{12}$ These experiments independently found that the Xe adatom preferentially binds to the low-coordinated on-top site instead of the high-coordinated hollow site on the metal surface. Motivated by the argument, a number of dynamical LEED experiments and density functional theory (DFT) calculations have been successively performed for Xe on closepacked metal surfaces, such as $\operatorname{Pt}(111),{ }^{13-17} \operatorname{Pd}(111),{ }^{17-19}$ $\mathrm{Cu}(111),{ }^{17,20,21} \mathrm{Cu}(110),{ }^{17,22}$ and $\mathrm{Ag}(001) .{ }^{23}$ From this, it was shown that Xe preferentially occupies the on-top site on the metal surface, mostly as a rule.

Compared to extensive investigations on the Xe/metal surface, the study of Xe/graphite is limited in recent years. A dynamical LEED observation indicated the hollow site preference for Xe on graphite, with an equilibrium distance of $3.59 \pm 0.05 \AA$ from $\mathrm{Xe}$ to the surface. ${ }^{24}$ To our best knowledge, there is no experimental information about the adsorption energy for $\mathrm{Xe}$ on graphite. In previous DFT studies, within the framework of local density approximation (LDA), the adsorption energy of

* To whom correspondence should be addressed. E-mail: take@ sci.hokudai.ac.jp (T.T.), shengli@hit.edu.cn (L.S.). Fax: 81-11-706-3535 (T.T.).

Harbin Institute of Technology.

* Hokkaido University.
$\mathrm{Xe}$ at the hollow site of the graphite surface was calculated as $-168^{25}$ and $-204 \mathrm{meV},{ }^{26}$ where the former value was evaluated by the all-electron full-potential linearized augmented plane wave plus local orbitals $(\mathrm{LAPW}+\mathrm{lo})$ method, whereas the latter was evaluated by the pseudopotential plane wave (PPPW) method. These studies employed a small unit cell for modeling the graphite surface where the distance between adjacent Xe adatoms is only about $4.26 \AA$, and the artificial interaction of two neighboring Xe adatoms might be introduced because the van der Waals radius of $\mathrm{Xe}$ is $2.16 \AA{ }^{7}$

In the most recent DFT-LDA/GGA calculations on the adsorption energy for $\mathrm{Xe}$ on the $\operatorname{Pd}(111)$ surface, ${ }^{19}$ even the superior GGA functionals predicted the hollow site preference, which is contrary to the experimental observation. ${ }^{18}$ Therefore, theoretical calculations beyond the DFT-LDA/GGA framework is required to evaluate the weak interaction of Xe/graphite quantitatively (it is noted, however, that new DFT approaches $^{27-29}$ have been successfully developed for treating dispersion interactions in noncovalent systems). It is well-known that London dispersion is a correlation phenomenon. Therefore, with a reasonable description of correlation, post-HartreeFock methods, such as the second-order Møller-Plesset perturbation theory (MP2) and the coupled cluster theory, including single, double (CCSD), and triple excitations [CCSD(T)], are proper alternatives for describing Xe/graphite interaction. Taking into account the computational cost, MP2 is the most feasible method to investigate the interaction in Xe/graphite.

The accurate prediction of physisorption of Xe on graphite also requires a suitable model to represent the graphite surface. The hydrogen-saturated cluster model is certainly an ideal choice because graphite is a typical covalent compound. ${ }^{30}$ In particular, the monolayer graphite (i.e., graphene) has been prepared in experiments, ${ }^{31}$ and it can be regarded as an infinite aromatic molecule. Polycyclic aromatic hydrocarbon (PAH) molecules have been successfully utilized in modeling the graphene surface. ${ }^{30}$ In this study, we performed ab initio MP2 calculations by using the $\mathrm{PAH}$ cluster model to determine accurately the site preference, equilibrium structures, and physisorption energies for $\mathrm{Xe}$ on the graphene surface. To analyze the site preference, the adsorption 


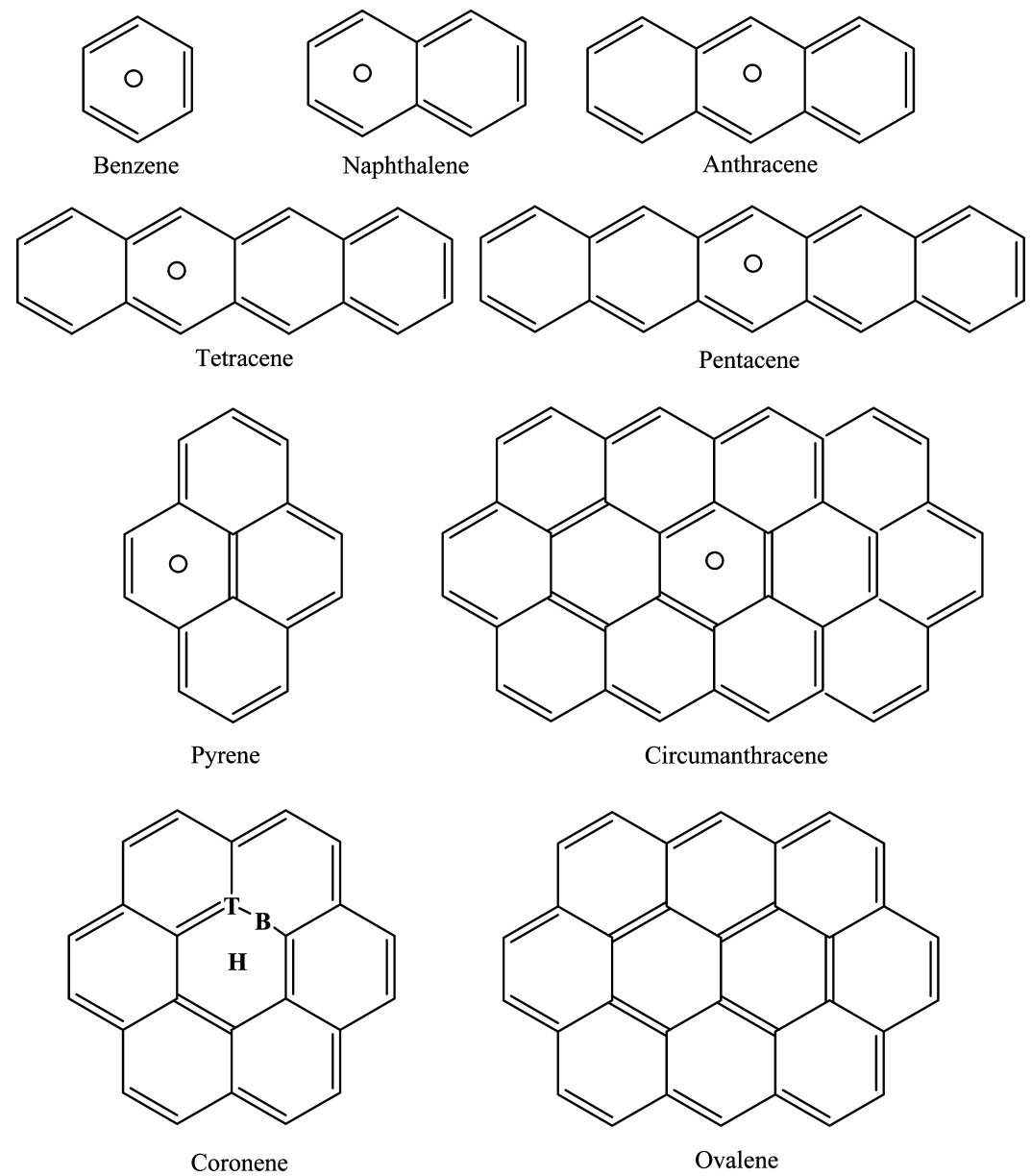

Figure 1. Polycyclic aromatic hydrocarbons (PAHs) used in this study. The open circle indicates the adsorption site, whereas H, T, and B stand for hollow, top, and bridge sites, respectively.

of two synthesized highly polar molecules, $\mathrm{XeF}$ and $\mathrm{XeBeO}$, on graphene was also investigated as the first report.

\section{Computational Methods}

The PAH molecules were chosen to model the graphene surface. To know the appropriate PAH size for modeling the graphene surface, the adsorption energies for Xe on a series of PAH molecules, starting from benzene to circumanthracene (Figure 1), were first calculated by the MP2 method using Dunning's cc-pVDZ basis sets ${ }^{32}$ for $\mathrm{C}$ and $\mathrm{H}$ atoms and the pseudopotential cc-pVDZ-PP basis $\operatorname{set}^{33}$ for the Xe atom. To check the effect of the basis set size and electronic structure methods on the interaction of $\mathrm{Xe}$-aromatic species, MP2, DFT $\left(\mathrm{BOP},{ }^{34} \mathrm{BOP}+\mathrm{LC},{ }^{35} \mathrm{~B} 3 \mathrm{LYP}^{36}\right)$, and $\operatorname{CCSD}(\mathrm{T})^{37}$ were then applied to the $\mathrm{Xe}-$ benzene system using cc-pVXZ for $\mathrm{C}$ and $\mathrm{H}$ and cc-pVXZ-PP for $\mathrm{Xe}(\mathrm{X}=\mathrm{D}, \mathrm{T}, \mathrm{Q})$, with and without diffuse functions. cc-pVXZ is denoted as VXZ, and aug-cc$\mathrm{pVXZ}$ (including diffuse functions) is denoted as AVXZ (X = $\mathrm{D}, \mathrm{T}, \mathrm{Q})$ in this paper. In all calculations, the geometry of the $\mathrm{PAH}$ molecules is fixed at a planar structure with a $\mathrm{C}-\mathrm{C}$ distance of $1.421 \AA$ and a $\mathrm{C}-\mathrm{H}$ distance of $1.07 \AA$; these values correspond to the experimental $\mathrm{C}-\mathrm{C}$ and $\mathrm{C}-\mathrm{H}$ bond lengths in graphite and benzene, ${ }^{38}$ respectively. The counterpoise (CP) corrections ${ }^{39}$ were applied to correct the basis set superposition error (BSSE). Finally, the adsorption energy was estimated from the $\mathrm{Xe} / \mathrm{PAH} \mathrm{CP}$-corrected pair potential, which was determined as a function of the $\mathrm{Xe}-\mathrm{PAH}$ distance, ranging from 2.0 to 7.0 $\AA$. Similar calculations were also performed for $\mathrm{XeBeO} /$ graphene and $\mathrm{XeF} /$ graphene systems. Pair potentials were
TABLE 1: Adsorption Energies $\left(E_{\text {ad }}\right.$ in $\mathrm{meV}$ ) and Equilibrium Distances $\left(d_{z}\right.$ in $\AA$ ) for Xe on PAH Molecules Calculated at the MP2//cc-pVDZ/cc-pVDZ-PP Level

\begin{tabular}{llc}
\hline \multicolumn{1}{c}{ PAH molecule } & \multicolumn{1}{c}{$E_{\text {ad }}$} & $d_{z}$ \\
\hline $\mathrm{C}_{6} \mathrm{H}_{6}$ (benzene) & -44.6 & 3.85 \\
$\mathrm{C}_{10} \mathrm{H}_{8}$ (naphthalene) & -60.8 & 3.75 \\
$\mathrm{C}_{14} \mathrm{H}_{10}$ (anthracene) & -80.8 & 3.66 \\
$\mathrm{C}_{18} \mathrm{H}_{12}$ (tetracene) & -96.3 & 3.64 \\
$\mathrm{C}_{22} \mathrm{H}_{14}$ (pentacene) & -101.7 & 3.63 \\
$\mathrm{C}_{16} \mathrm{H}_{10}$ (pyrene) & -82.4 & 3.66 \\
$\mathrm{C}_{24} \mathrm{H}_{12}$ (coronene) & -126.2 & 3.57 \\
$\mathrm{C}_{32} \mathrm{H}_{14}$ (ovalen) & -134.9 & 3.56 \\
$\mathrm{C}_{40} \mathrm{H}_{16}$ (circumanthracene) & -143.8 & 3.54
\end{tabular}

calculated by Gamess, ${ }^{40}$ whereas NBO charges and dipole moments were calculated by Gaussian $03 .^{41}$

\section{Results and Discussion}

Table 1 shows the adsorption energies and equilibrium geometries of Xe on nine PAH molecules (Figure 1) calculated at the MP2//VDZ/VDZ-PP level. It is shown that there is a notable correlation between the PAH size and adsorption energy. As the size of the PAHs increases, the adsorption energy sharply increases while the equilibrium distance from Xe to the center of the PAH decreases gradually. The adsorption energy of Xe for the smallest and the largest PAH molecules was calculated as $-44.6 \mathrm{meV}$ (benzene) and $-143.8 \mathrm{meV}$ (circumanthracene), respectively. This is a relatively large difference, but it tends to converge when the size of the PAH exceeds the size of coronene; the adsorption energies for Xe/ovalene and $\mathrm{Xe} /$ 
(a)

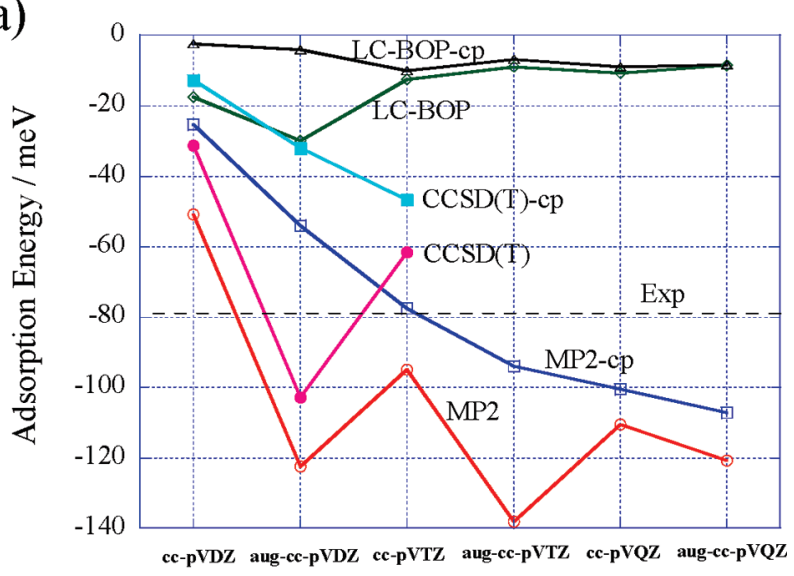

(b)

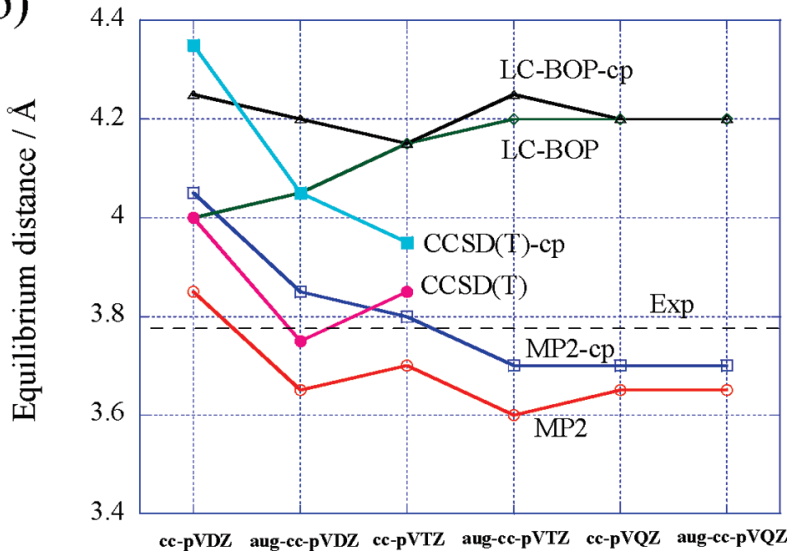

Figure 2. (a) Adsorption energies and (b) equilibrium distances of Xe/benzene calculated by MP2, LC-BOP, CCSD(T), and the corresponding counterpoise-corrected methods with Dunning's correlationconsistent basis sets, cc-pVXZ, and aug-cc-pVXZ $(\mathrm{X}=\mathrm{D}, \mathrm{T}, \mathrm{Q})$.

circumanthracene show a very small difference, $8.9 \mathrm{meV}$. On the basis of this finding, coronene was employed as a model to represent the graphene surface. Actually, coronene has been successfully employed in theoretical studies of physisorption of small atoms (or molecules) on the graphene surface. ${ }^{42,43}$ In these studies, geometrical parameters of coronene were fixed with experimental data for $\mathrm{C}-\mathrm{C}$ and $\mathrm{C}-\mathrm{H}$ bond lengths as the interaction energy in physisorption is so small that the adsorbate does not affect the substrate geometries noticeably. To check the effect of geometrical relaxation on the site preference, we carried out preliminary MP2/VDZ calculations using the relaxed and nonrelaxed coronene model and verified that the order for the adsorption energies were unchanged $\left(E_{\mathrm{ad}}\right.$ (hollow) $>E_{\mathrm{ad}}$ (bridge) $>E_{\text {ad }}$ (on-top)). Therefore, we decided to fix the geometry of coronene to the isolated one.

To examine the effects of the electronic structure method and basis sets on the interaction in the $\mathrm{Xe} / \mathrm{PAH}$ system, we performed systematic calculations using MP2, DFT, and CCSD(T) methods with Dunning's correlation-consistent basis sets for $\mathrm{Xe}$-benzene. $\mathrm{CCSD}(\mathrm{T})$ calculations are performed with only VDZ, AVDZ, and VTZ basis sets because of huge computational costs. Figure 2 describes the dependence of adsorption energies and equilibrium distances on the size of the basis sets, and Table 2 presents the MP2 results in detail. In DFT calculations, PBE and LC-BOP methods presented very small interaction energies, whereas B3LYP and BOP methods gave no binding for the Xe/benzene system. One possible way to improve this weak interaction in the DFT scheme is to include
TABLE 2: MP2 Adsorption Energies $\left(E_{\text {ad }}\right.$ in $\left.\mathrm{meV}\right)$ and Equilibrium Distances $\left(d_{z}\right.$ in $\AA$ ) for the Xe/Benzene System

\begin{tabular}{llllll}
\hline \multirow{2}{*}{ basis set } & \multicolumn{2}{c}{ CP-corrected } & & \multicolumn{2}{c}{ no correction } \\
\cline { 2 - 3 } \cline { 5 - 6 } & $E_{\text {ad }}$ in meV & $d_{z}$ in $\AA$ & & $E_{\text {ad }}$ in meV & $d_{z}$ in $\AA$ \\
\hline cc-pVDZ & -25.4 & 4.07 & & -50.9 & 3.85 \\
aug-cc-pVDZ & -54.1 & 3.86 & & -122.6 & 3.67 \\
cc-pVTZ & -77.7 & 3.78 & & -94.9 & 3.71 \\
aug-cc-pVTZ & -94.1 & 3.72 & & -138.2 & 3.61 \\
cc-pVQZ & -100.5 & 3.69 & & -110.8 & 3.66 \\
aug-cc-pVQZ & -107.2 & 3.68 & & -120.8 & 3.63 \\
exptl $^{a}$ & -78.7 & 3.77 & &
\end{tabular}

${ }^{a}$ The experimental value is taken from ref 44 .

TABLE 3: Adsorption Energies $\left(E_{\text {ad }}\right.$ in meV) and Equilibrium Distances $\left(d_{z}\right.$ in $\AA$ ) for Xe on Graphene at the MP2//cc-pVTZ/cc-pVDZ-PP Level

\begin{tabular}{|c|c|c|c|c|}
\hline \multirow{2}{*}{$\begin{array}{l}\text { adsorption } \\
\text { site }\end{array}$} & \multicolumn{2}{|c|}{ CP-corrected } & \multicolumn{2}{|c|}{ no correction } \\
\hline & $E_{\text {ad }}$ & $d_{z}$ & $E_{\text {ad }}$ & $d_{z}$ \\
\hline hollow & -142.9 & 3.56 & -226.1 & 3.40 \\
\hline bridge & -130.8 & 3.60 & -208.7 & 3.44 \\
\hline top & -127.4 & 3.61 & -204.1 & 3.45 \\
\hline exptl & & $3.59 \pm 0.05^{a}$ & & \\
\hline
\end{tabular}

${ }^{a}$ The experimental value is taken from ref 24 for Xe adsorption at the hollow site.

the van der Waals correlation functional. In ab initio calculations, the counterpoise-corrected MP2 (MP2-cp) adsorption energy tends to converge with increasing size of the basis set; the adsorption energy is evaluated as $-94.1,-100.5$, and $-107.2 \mathrm{meV}$ for AVTZ, VQZ, and AVQZ, respectively. For the largest basis set, AVQZ, the BSSE is shown to be $13.8 \mathrm{meV}$. As for the equilibrium distance, MP2 calculations also show a good convergence as the size of the basis set increases.

In experimental study for the Xe/benzene system, ${ }^{44}$ the adsorption energy and the equilibrium distance were reported as -78.7 meV and $3.77 \AA$, respectively. The CP-corrected MP2/VTZ results $(-77.7 \mathrm{meV}$ and $3.78 \AA)$ are in excellent agreement with the experimental ones, whereas the MP2/AVQZ calculation obviously overestimates the adsorption energy by about $27 \mathrm{meV}$. Our MP2 calculations are consistent with the general acceptance that the MP2 theory with a moderately large basis set can describe such weakly bound systems with sufficient accuracy. ${ }^{45}$ As shown in Figure 2, $\operatorname{CCSD}(\mathrm{T})$-cp results definitely approach the experimental adsorption energy with increasing size of the basis set, but CCSD(T) calculations with large basis sets are computationally expensive, even for the $\mathrm{Xe}$-benzene system. An interesting finding from Figure 2 and Table 2 is that the calculated values with the VXZ $(\mathrm{X}=\mathrm{D}, \mathrm{T}, \mathrm{Q})$ basis sets without $\mathrm{CP}$ correction for BSSE are very close to those obtained with the AVXZ basis sets with $\mathrm{CP}$ correction. For instance, MP2 energies with VTZ and AVTZ plus $\mathrm{CP}$ correction are -94.9 and $-94.1 \mathrm{meV}$, respectively. CCSD(T) results show the same tendency, where the adsorption energies with VDZ and AVDZ plus CP correction are -31.4 and $-32.0 \mathrm{meV}$, respectively. Taking into account the above findings, we decided to employ the MP2//VTZ/VDZ-PP method, which is expected to give the results close to CP-corrected MP2/AVTZ calculations. For other systems, however, we reduced the basis set size to VDZ to provide qualitative analysis for the savings of computational cost.

Table 3 shows the adsorption energy and the equilibrium distance for Xe adsorption on graphene, calculated at the MP2// VTZ/VDZ-PP level, using the coronene model. We obtained the CP-corrected MP2 adsorption energy of $-142.9 \mathrm{meV}$, whereas the previous calculation with LDA/LAPW $+\mathrm{lo}^{25}$ and LDA/PPPW ${ }^{26}$ basis sets reported -168.0 and $-204.0 \mathrm{meV}$, respectively. The 
TABLE 4: MP2 NBO Charges and Dipole Moments (in debye) Calculated at the VDZ/VDZ-PP Level

\begin{tabular}{|c|c|c|c|c|c|}
\hline \multicolumn{6}{|c|}{ Xe/graphene } \\
\hline NBO charge & hollow site & on-top site & bridge site & & \\
\hline $\begin{array}{l}\mathrm{Xe} \\
\text { dipole }\end{array}$ & $\begin{array}{l}0.0042 \\
0.123\end{array}$ & $\begin{array}{l}0.0038 \\
0.125\end{array}$ & $\begin{array}{l}0.0039 \\
0.123\end{array}$ & & \\
\hline \multicolumn{6}{|c|}{ XeBeO/graphene } \\
\hline NBO charge & hollow site & on-top site & bridge site & $\mathrm{XeBeO}^{a}$ & $\mathrm{BeO}^{a}$ \\
\hline $\begin{array}{l}\mathrm{O} \\
\mathrm{Be} \\
\mathrm{Xe} \\
\text { dipole }\end{array}$ & $\begin{array}{c}-1.5737 \\
1.3979 \\
0.1739 \\
10.87\end{array}$ & $\begin{array}{c}-1.5740 \\
1.3979 \\
0.1737 \\
10.98\end{array}$ & $\begin{array}{c}-1.5737 \\
1.3968 \\
0.1746 \\
10.92\end{array}$ & $\begin{array}{c}-1.5610 \\
1.3941 \\
0.1669 \\
9.52\end{array}$ & $\begin{array}{r}-1.5600 \\
1.5600 \\
6.37\end{array}$ \\
\hline \multicolumn{6}{|c|}{ XeF/graphene } \\
\hline NBO charge & hollow site & on-top site & bridge site & $\mathrm{XeF}^{a}$ & \\
\hline $\begin{array}{l}\mathrm{F} \\
\mathrm{Xe} \\
\text { dipole }\end{array}$ & $\begin{array}{c}-0.6814 \\
0.6835 \\
4.58\end{array}$ & $\begin{array}{c}-0.6862 \\
0.6857 \\
4.70\end{array}$ & $\begin{array}{c}-0.6867 \\
0.6868 \\
4.69\end{array}$ & $\begin{array}{c}-0.6509 \\
0.6506 \\
3.73\end{array}$ & \\
\hline
\end{tabular}

${ }^{a}$ The geometries are optimized by MP2 using the AVQZ basis set for Be, O, and F atoms and the VDZ-PP basis set for the Xe atom.

LDA approach overestimates the interaction energy compared with our MP2 results. As for ab initio calculations, the MP2 adsorption energy approaches the converged result only with large augmented basis sets, but such calculation is too expensive. As discussed above, however, we can estimate the converged adsorption energy by using a moderate basis set. For the Xe/graphene system, the MP2/VTZ adsorption energy without CP correction would be very similar to that of CP-corrected MP2/AVTZ, as found in the study of the $\mathrm{Xe}$-benzene system. Thus, the MP2/VTZ value, -226.1 meV, could approach much more closely to the CP-corrected MP2/ AVTZ result. This is expected as a converged adsorption energy for Xe/graphene at the MP2 level because the adsorption energy has been found to converge by the AVTZ basis set for the Xe/ benzene system. Considering that the MP2 method usually overestimates the interaction energy, ${ }^{46}$ we believe that the $\mathrm{CP}$ corrected MP2/VTZ value of $-142.9 \mathrm{meV}$ is more reasonable to estimate the correct adsorption energy of Xe/graphene because, at the same level of theory, the calculated interaction energy of Xe/ benzene is in excellent agreement with the experimental result. Also, the CP-corrected MP2/VTZ equilibrium distance of $3.56 \AA$ is in very good agreement with the measured value of $3.59 \pm 0.05$ $\AA^{24}$ for Xe adsorption at the hollow site of the graphene surface. In the two DFT-LDA studies, the equilibrium distance was reported as $3.497 \AA$ in ref 25 and $3.60 \AA$ in ref 26 .

The present MP2 calculations doubtlessly show that Xe preferentially binds to the hollow site, which is more stable in energy (about $15.5 \mathrm{meV}$ ) than the on-top site and more stable (about $12.1 \mathrm{meV}$ ) than the bridge site. Our MP2 adsorption energies are fairly different from those calculated by LDA/ LAPW + lo $(6.24 \text { and } 5.51 \mathrm{meV})^{25}$ and LDA/PPPW methods (4.9 and $2.2 \mathrm{meV}) .^{26}$ The zero-point vibrational energies (ZPVE) for the $\mathrm{Xe}$-graphene intermolecular stretching mode were also calculated by the numerical differentiation of energy for the purposes of evaluating the site preference. The ZPVE values were calculated as $2.73,2.65$, and $2.67 \mathrm{meV}$ for hollow, bridge, and on-top sites, respectively. The difference between ZPVE at the three adsorption sites is so small that it does not change the site preference for the Xe/graphene system.

The hollow site preference for Xe adsorption on graphene can be analyzed from the electronic structure of the substrate. Table 4 shows natural bond orbital (NBO) charges and induced dipole moments calculated at the MP2 level. In graphene, each carbon atom can donate an electron through a $\mathrm{p}_{z}$ orbital that forms an aromatic $\pi$-bond structure above and below the six- membered ring. Because of delocalized $\pi$ electrons, graphene has donor-like character at the on-top region, while it has acceptor-like character at the hollow region. When the neutral Xe atom approaches the graphene surface, the induced dipole moment is quite small at the three sites, and their values are almost equal to each other, as shown in Table 4. This result shows that the attractive interactions at the three sites are not so different from each other, while the Pauli repulsion force, naturally, drives the adatom to the hollow site, which tends to accommodate the valence electrons of Xe. In Table 4, the partially positive NBO charge on the Xe adatom indicates that the electrons are transferred to the substrate. Such a situation is just contrary to the case of Xe adsorption on a close-packed transition-metal surface, in which the charge is partially transferred to the adsorbate. This indicates that $d$ electrons of metal atoms play a donor-like role and thus Xe binds to the on-top site on the metal surface. Owing to the high polarizability, $\mathrm{d}$ electrons can efficiently reduce the repulsion interaction and contribute to the stronger attractive interaction between $\mathrm{Xe}$ and the metal surface. ${ }^{19}$ Because graphene does not have such $\mathrm{d}$ orbital valence electrons, it only provides the hollow site to accept the Xe adatom. Therefore, Xe binds to the on-top site on the metal surface, but to the hollow site on graphene.

The analysis is further supported by additional calculations on the adsorption of two polar molecules, $\mathrm{XeBeO}$ and $\mathrm{XeF}$, on graphene. The dipole moments are calculated as 9.52 and 3.73 $\mathrm{D}$ for $\mathrm{XeBeO}$ and $\mathrm{XeF}$, respectively, as shown in Table 4. For $\mathrm{XeBeO}$, the electron-withdrawing ability of the $\mathrm{BeO}$ group is so strong that the charge is partially transferred from the $\pi$ system of the graphene surface to the adsorbate. This case is similar to the $\mathrm{Xe} / \mathrm{metal}$ system, in which the strongly polarized $\mathrm{XeBeO}$ is natural to adsorb at the on-top site where graphene donates its aromatic $\pi$ electrons. As for $\mathrm{XeF}$, the electronwithdrawing ability of the adsorbate is moderate, and the competition for electrons between $\mathrm{XeF}$ and the $\pi$ system of graphene compromises so that charge transfer does not arise, even at the on-top and bridge sites. Hence, there is no strong indication for the adsorption site preference, which is consistent with the calculated adsorption energy. The MP2 results for XeF/ graphene and $\mathrm{XeBeO} /$ graphene are presented in Table 5. For the former, the difference of adsorption energies at the three sites is quite small (within $2 \mathrm{meV}$ ), whereas for the latter, the adsorption energy at the on-top site is more stable by about 41.5 and $33.9 \mathrm{meV}$ than at the hollow and bridge sites, 
TABLE 5: MP2 Adsorption Energies $\left(E_{\text {ad }}\right.$ in $\left.\mathrm{meV}\right)$ and Equilibrium Distances $\left(d_{z}\right.$ in $\AA$ ) for $\mathrm{XeF}$ and $\mathrm{XeBeO}$ on Graphene Given by MP2 Calculations

\begin{tabular}{|c|c|c|c|c|c|c|c|c|}
\hline & \multicolumn{4}{|c|}{$\mathrm{XeF}^{a}$ /graphene } & \multicolumn{4}{|c|}{$\mathrm{XeBeO}^{a}$ /graphene } \\
\hline & \multicolumn{2}{|c|}{$\mathrm{CP}$-corrected } & \multicolumn{2}{|c|}{ no correction } & \multicolumn{2}{|c|}{$\mathrm{CP}$-corrected } & \multicolumn{2}{|c|}{ no correction } \\
\hline & $E_{\text {ad }}$ & $d_{z}$ & $E_{\text {ad }}$ & $d_{z}$ & $E_{\text {ad }}$ & $d_{z}$ & $E_{\text {ad }}$ & $d_{z}$ \\
\hline & -233.2 & 3.51 & -297.3 & 3.38 & -321.0 & 3.44 & -442.1 & 3.31 \\
\hline bridge & -235.4 & 3.47 & -302.8 & 3.34 & -328.6 & 3.43 & -426.9 & 3.31 \\
\hline top & -235.2 & 3.46 & -303.3 & 3.33 & -362.5 & 3.37 & -446.0 & 3.33 \\
\hline
\end{tabular}

${ }^{a}$ The $\mathrm{XeF}$ and $\mathrm{XeBeO}$ geometries are optimized by MP2 using the AVQZ basis set for $\mathrm{Be}, \mathrm{O}$, and $\mathrm{F}$ atoms and the VDZ-PP basis set for the Xe atom.

respectively. It is noted that, for $\mathrm{Xe}$ on graphene, the adsorption energy at the hollow site is greater by 15.5 and $12.1 \mathrm{meV}$ than at the on-top site and bridge site, respectively. Therefore, the adsorption site preference for rare-gas atoms or molecules on a solid surface mostly depends on the electronic character of the adsorbate and substrate, which determines the competition between the attraction and repulsion interactions in the adsorption process.

\section{Conclusion}

In this paper, we presented a systematic ab initio MP2 study for $\mathrm{Xe}, \mathrm{XeBeO}$, and $\mathrm{XeF}$ adsorption on the graphene surface. After performing test calculations to examine the effects of the electronic structure method, the basis sets, and the model size, we decided to employ the MP2 method with Dunning's ccpVTZ/cc-pVDZ-PP basis sets to evaluate the physisorption energy and geometry for the Xe/graphene system, while considering the compromise of accuracy and efficiency. At this computational level, the adsorption energy of $\mathrm{Xe}$ on graphene was calculated as $-142.9,-130.8$, and $-127.4 \mathrm{meV}$ at the hollow, bridge, and on-top sites, respectively, and the equilibrium distance was calculated as $3.56 \AA$ for Xe adsorption at the hollow site, which was in excellent agreement with the dynamical LEED experimental value of $3.59 \pm 0.05 \AA$. Our MP2 results clearly show that Xe preferentially binds to the hollow site. Through comparisons of the $\mathrm{Xe}, \mathrm{XeBeO}$, and $\mathrm{XeF}$ adsorptions on the graphene surface, it is shown that the electronic character of the adsorbate and substrate determines the adsorption site preference, which results from the compromise of the attraction and repulsion interactions.

Acknowledgment. This work was supported, in part, by a Grant-in-Aid for Scientific Research from the Ministry of Education, Science and Culture, Japan, and by the National Science Foundation of China (Grant No. 20903029). L.S. would also like to thank the Japan Society for the Promotion of Science for Research Fellowships for Young Scientists.

\section{References and Notes}

(1) Carlos, W. E.; Cole, M. W. Surf. Sci. 1980, 91, 339.

(2) Cerdá, J. R.; de Andres, P. L.; Flores, F.; Perez, R. Phys. Rev. B 1992 45,8721 .

(3) Rejto, P. A.; Andersen, H. C. J. Chem. Phys. 1993, 98, 7636

(4) Potthoff, M.; Hilgers, G.; Müller, N.; Heinzmann, U.; Haunert, L.; Braun, J.; Borstel, G. Surf. Sci. 1995, 322, 193.

(5) Hilgers, G.; Potthoff, M.; Müller, N.; Heinzmann, U. Surf. Sci. 1995, 322, 207.

(6) Bruch, L. W.; Cole, M. W.; Zaremba, E. Physical Adsorption: Forces and Phenomena; Oxford Science: Oxford, U.K., 1997.

(7) Bondi, A. J. Phys. Chem. 1964, 68, 441.

(8) Horch, S.; Zeppenfeld, P.; Comsa, G. Appl. Phys. A: Mater. Sci. Process. 1995, 60, 147.

(9) Narloch, B.; Menzel, D. Chem. Phys. Lett. 1997, 270, 163.
(10) Narloch, B.; Menzel, D. Surf. Sci. 1998, 412, 562.

(11) Seyller, Th.; Caragiu, M.; Diehl, R. D.; Kaukasoina, P.; Lindroos, M. Chem. Phys. Lett. 1998, 291, 567.

(12) Seyller, Th.; Caragiu, M.; Diehl, R. D.; Kaukasoina, P.; Lindroos, M. Phys. Rev. B 1999, 60, 11084.

(13) Müller, J. E. Phys. Rev. Lett. 1990, 65, 3021.

(14) Betancourt, A. E.; Bird, D. M. J. Phys.: Condens. Matter 2000, 12, 7077 .

(15) Da Silva, J. L. F.; Stampfl, C.; Scheffler, M. Phys. Rev. Lett. 2003, 90, 066104.

(16) Da Silva, J. L. F.; Stampfl, C.; Scheffler, M. Phys. Rev. B 2005, 72, 075424

(17) Diehl, R. D.; Seyller, Th.; Caragiu, M.; Leatherman, G. S.; Ferralis, N.; Pussi, K.; Kaukasoina, P.; Lindroos, M. J. Phys.: Condens. Matter 2004, 16, S2839.

(18) Caragiu, M.; Seyller, Th.; Diehl, R. D. Phys. Rev. B 2002, 66, 195411.

(19) Da Silva, J. L. F.; Stampfl, C. Phys. Rev. B 2008, 77, 045401.

(20) Bagus, P. S.; Staemmler, V.; Wöll, C. Phys. Rev. Lett. 2002, 89, 096104

(21) Righi, M. C.; Ferrario, M. J. Phys.: Condens. Matter 2007, 19, 305008 .

(22) Caragiu, M.; Seyller, Th.; Diehl, R. D. Surf. Sci. 2003, 539, 165.

(23) Clarke, S.; Bihlmayer, G.; Blügel, S. Phys. Rev. B 2001, 63, 085416.

(24) Pussi, K.; Smerdon, J.; Ferralis, N.; Lindroos, M.; MacGrath, R.; Diehl, R. D. Surf. Sci. 2004, 548, 157.

(25) Da Silva, J. L. F.; Stampfl, C. Phys. Rev. B 2007, 76, 085301.

(26) Chen, X.-R.; Zhou, X.-L.; Zhu, J.; Gou, Q.-Q. Phys. Lett. A 2003, $315,403$.

(27) Grimme, S. J. Comput. Chem. 2004, 25, 1463.

(28) Thonhauser, T.; Cooper, V. R.; Li, S.; Puzder, A.; Hyldgaard, P.; Langreth, D. C. Phys. Rev. B 2007, 76, 125112.

(29) Tkatchenko, A.; Scheffler, M. Phys. Rev. B 2009, 102, 073005.

(30) Jug, K.; Bredow, T. J. Comput. Chem. 2004, 25, 1551.

(31) Novoselov, K. S.; Geim, A. K.; Morozov, S. V.; Jiang, D.; Zhang, Y.; Dubonos, S. V.; Grigorieva, I. V.; Firsov, A. A. Science 2004, 306, 5696.

(32) Dunning, T. H., Jr. J. Chem. Phys. 1989, 90, 1007.

(33) Peterson, K. A.; Figgen, D.; Goll, E.; Stoll, H.; Dolg, M. J. Chem. Phys. 2003, 119, 11113.

(34) (a) Becke, A. D. Phys. Rev. A 1988, 38, 3098. (b) Tsuneda, T.; Hirao, T. Chem. Phys. Lett. 1997, 268, 510. (c) Tsuneda, T.; Suzumura, T.; Hirao, K. J. Chem. Phys. 1999, 110, 10664.

(35) Iikura, H.; Tsuneda, T.; Yanai, T.; Hirao, K. J. Chem. Phys. 2001, 115,3540 .

(36) Becke, A. D. J. Chem. Phys. 1993, 98, 5648. Stephens, P. J.; Devlin, F. J.; Chablowski, C. F.; Frisch, M. J. J. Phys. Chem. 1994, 98, 11623. Hertwig, R. H.; Koch, W. Chem. Phys. Lett. 1997, 268, 345.

(37) Piecuch, P.; Kucharski, S. A.; Kowalski, K.; Musial, M. Comput. Phys. Commun. 2002, 149, 71

(38) Weast, R. C., Ed. Handbook of Chemistry and Physics, 64th ed.; CRC Press: Boca Raton, FL, 1983.

(39) Boys, S. F.; Bernardi, F. Mol. Phys. 1970, 19, 553.

(40) Schmidt, M. W.; Baldridge, K. K.; Boatz, J. A.; Elbert, S. T.; Gordon, M. S.; Jensen, J. J.; Koseki, S.; Matsunaga, N.; Nguyen, K. A.; Su, S.; Windus, T. L.; Dupuis, M.; Montgomery, J. A. J. Comput. Chem. 1993, 14, 1347.

(41) Frisch, M. J.; Trucks, G. W.; Schlegel, H. B.; Scuseria, G. E.; Robb, M. A.; Cheeseman, J. R.; Montgomery, J. A., Jr.; Vreven, T.; Kudin, K. N.; Burant, J. C.; Millam, J. M.; Iyengar, S. S.; Tomasi, J.; Barone, V.; Mennucci, B.; Cossi, M.; Scalmani, G.; Rega, N.; Petersson, G. A.; Nakatsuji, H.; Hada, M.; Ehara, M.; Toyota, K.; Fukuda, R.; Hasegawa, J.; Ishida, M.; Nakajima, T.; Honda, Y.; Kitao, O.; Nakai, H.; Klene, M.; Li, X.; Knox, J. E.; Hratchian, H. P.; Cross, J. B.; Bakken, V.; Adamo, C.; Jaramillo, J.; Gomperts, R.; Stratmann, R. E.; Yazyev, O.; Austin, A. J.; Cammi, R.; Pomelli, C.; Ochterski, J. W.; Ayala, P. Y.; Morokuma, K.; Voth, G. A.; Salvador, P.; Dannenberg, J. J.; Zakrzewski, V. G.; Dapprich, S.; Daniels, A. D.; Strain, M. C.; Farkas, O.; Malick, D. K.; Rabuck, A. D.; Raghavachari, K.; Foresman, J. B.; Ortiz, J. V.; Cui, Q.; Baboul, A. G.; Clifford, S.; Cioslowski, J.; Stefanov, B. B.; Liu, G.; Liashenko, A.; Piskorz, P.; Komaromi, I.; Martin, R. L.; Fox, D. J.; Keith, T.; Al-Laham, M. A.; Peng, C. Y.; Nanayakkara, A.; Challacombe, M.; Gill, P. M. W.; Johnson, B.; Chen, W.; Wong, M. W.; Gonzalez, C.; Pople, J. A. Gaussian 03, revision C.02; Gaussian, Inc.: Wallingford, CT, 2004.

(42) Bonfani, M.; Martinazzo, R.; Tantardini, G. F.; Ponti, A. J. Phys. Chem. C 2007, 111, 5825

(43) Tran, F.; Weber, J.; Wesolowski, T.; Cheikh, F.; Ellinger, V.; Pauzat, F. J. Phys. Chem. B 2002, 106, 8689.

(44) Brupbacher, T.; Makarewicz, J.; Bauder, A. J. Chem. Phys. 1994, 101, 9736.

(45) Patchkovskii, S.; Tse, J. S.; Yurchenko, S. N.; Zhenchkov, L.; Heine, T.; Seifet, G. Proc. Natl. Acad. Sci. U.S.A. 2005, 102, 10439.

(46) Koch, H.; Fernández, B.; Christiansen, O. J. Chem. Phys. 1998, 108, 2784.

JP907861C 